\title{
Comparison between peripherally inserted central venous catheters (PICC) and short-term central venous catheter (ST-CVC) in patients discharged from Intensive Care Unit (ICU)
}

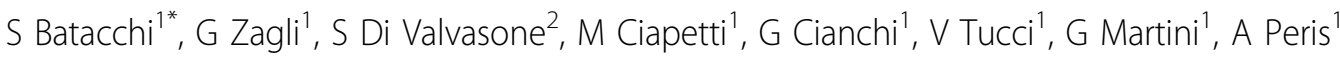 \\ From 30th International Symposium on Intensive Care and Emergency Medicine \\ Brussels, Belgium. 9-12 March 2010
}

\section{Correction}

After the publication of this abstract [1], we found some mistakes in the text. In details:

Introduction section: the correct sentence is "The aim of our study was to assess the rate of complications (deep venous thrombosis, DVT; infections) in patients discharged from Intensive Care Unit (ICU) with a PICC or a ST-CVC."

Methods section: the study period is "Jan 2008 to Aug 2008".

Results section: the sentence with correct data is "Admission diagnosis in PICC and ST-CVC groups were also similar: major trauma (38.6\% vs $44.8 \%)$, sepsis $(40.3 \%$ vs $34.4 \%)$, post-surgical complications $(21.1 \%$ vs 20.8\%). Total PICCs catheter day were 4024, whereas total ST-CVC catheter days were 2764. Despite similar demographic and clinical caractheristics, PICC group showed a significantly higher rate of DVT than ST-CVC group (27.2\% vs 9.6\%; P < 0.01)."
We regret any inconvenience that this inaccuracy may have caused.

\section{Author details}

${ }^{1}$ Careggi Teaching Hospital, Anaesthesia and Intensive Care Unit of Emergency Department, Florence, Italy. ${ }^{2}$ University of Florence, Postgraduate School of Anesthesia and Intensive Care, Florence, Italy.

Published: 7 April 2010

\section{Reference}

1. Batacchi S, Zagli G, Di Valvasone S, Ciapetti M, Cianchi G, Tucci V, Martini G, Peris A: Comparison between peripherally inserted central venous catheters (PICC) and short-term central venous catheter (ST-CVC) in patients discharged from Intensive Care Unit (ICU). Critical Care 2010, 14(Suppl 1):P388.

\section{doi:10.1186/cc8922}

Cite this article as: Batacchi et al:: Comparison between peripherally inserted central venous catheters (PICC) and short-term central venous catheter (ST-CVC) in patients discharged from Intensive Care Unit (ICU). Critical Care 2010 14(Suppl 1):P604.
${ }^{1}$ Careggi Teaching Hospital, Anaesthesia and Intensive Care Unit of Emergency Department, Florence, Italy
Submit your next manuscript to BioMed Central and take full advantage of:

- Convenient online submission

- Thorough peer review

- No space constraints or color figure charges

- Immediate publication on acceptance

- Inclusion in PubMed, CAS, Scopus and Google Scholar

- Research which is freely available for redistribution

Submit your manuscript at www.biomedcentral.com/submit
C Biomed Central 